\title{
XVIII. An essay on bleaching; with the description of a new method of bleaching by steam according to the process of C. Chaptal; and on its application to the arts
}

\section{R. O'Reilly}

To cite this article: R. O'Reilly (1801) XVIII. An essay on bleaching; with the description of a new method of bleaching by steam according to the process of C. Chaptal; and on its application to the arts, Philosophical Magazine Series 1, 10:38, 97-111, DOI: $10.1080 / 14786440108675899$

To link to this article: http://dx.doi.org/10.1080/14786440108675899

\section{Published online: 18 May 2009.}

\section{Submit your article to this journal $\sqsubset$}

\section{山 Article views: 2}




\section{[ 97 ]}

XVIII. An Effay on Bleacbing; with the Defcription of a new Metbod of Bleaching by Steam. according to the Procefs of C. Ch A pTaL; and on its Application to the Arts. By R. O'Reilty, of tbe Academy of Bologna, Member of the Lycaum of the Arts, Ëc.

T

$\mathrm{HE}$ art of bleaching is one of thofe connected with the firft ideas of civilization. The theory on which it is founded was entirely unknown to the antients; but the Egyptians were acquainted with the deterfive quality of fome kinds of clay, and the effect produced by the atmofphere, moifture, and light, on the ftuffs expofed to their action.

Health and cleanlinefs rendered it neceffary to devife quicker means than thefe; and the property of foap and leys of alhes were therefore foon difcovered.

In the prefent age, the arts, following fcience with clofe fteps, have taken advantage of proceffes and deterfive menftrua, the exiftence of which was before unknown: thefe difcoveries have fucceeded each other with fuch rapidity, that the laft fix years have effected a complete revolution in the art of bleaching.

This art divides itfelf very naturally into two quite diftinet branches, which we thall avoid confounding. One of them comprehends the bleaching of animal fubftances; the other, that of verretable matters. We thall treat of thefe fubjects feparately, as well as of the different menftrua and deterfive fubftances generally employed.

\section{Bleacbing of Animal Subfaxces.}

The fubftances produced by the animal kingdom, which are more particularly employed as veftments, differ effentially from thofe of the vegetable kingdom. It is on a knowledge of the moft ftriking traits, which form the line of demarcation between the two kingdoms, that the art of bleaching is founded.

Vegetables ferve as nourifhment to the animals and infects the fpoils of which we employ. Animalized by their organs they acquire other properties. Azote, in particular, feems to be their moft diftinguifhing character: it is fcarcely found in vegetable fubftances. To this principle we may add the exiftence of fulphur and phofphorus, which form fo many

VOL. X. fources

Phil. Mag. No. $3^{8 .}$ July 1801. 
fources for thofe peftilential exhalations with which the decompofition of animal matters, by putrid fermentation, is always accompanied.

The affinity of aggregation of thefe fubftances, or that law of adhefion which keeps their moleculæ together, is weaker than in the vegetable kingdom; for this reafon they are fo eafily diffolved and deftroyed by acids and alkalies, and hence the readinefs with which aerriform fluids are produced.

The bleaching of animal fubftances requires the concurrence of alkalies, foap, ammonia, and fulphurous acid. We thall here confine ourfelves to an examination of wool and filk, as the animal fubftances moft generally employed, and which it is of importance that manufacturers thould be acquainted with the method of bleaching in the moft ceconomical and moft expeditious manner.

\section{of Wool.}

Wool is a kind of hair with which the bodies of feveral animals are covered. It is compofed of filaments or tubes filled with an oily or medullary fubftance. The fides of thefe tubes are perforated with a multitude of fmall pores, which communicate with the Iongitudinal tube. By chemical analyfis wool gives a great deal of oil and carbonate of ammonia: cauftic alkatine leys deftroy it entirely; and it is to the facility with which it diffolves in alkalies that we are indebted for the noble difcovery, made by C. Chaptal, of the foap of wool. Wool experiences no change in boiling water: this obfervation is of great importance, in regard to the art of which we are now treating; it alters very little when preferved in a place well aired; acids have very little action on it; when expofed to a ftrong heat it enters into fufion. All thefe faets united prove that wool is a femi-oleaginous fubftance. The greafe with which it is covered when on the body of the animal, and from which it is freed by fcouring, ferves to confirm this affertion.

An examination of thefe chemical facts is neceffary for underftanding the principles which ought to direct the artift in the bleaching of this fubftance. The little action which acids have upon wool, and its unalterability in water, even when aided by caloric, render it neceffary to have recourfe to alkaline or faponaceous leys; but its folubility in thefe falts thows that great prudence and caution muft be employed. In regard to acids, none have been hitherto ufed but the fulphurous acid obtained in the gafeous ftate by combuftion. 
Of the Bleacbing of Wool.

In the preliminary operations to which wool is fubjected, it is cuftomary to leave a little of its greafe to fecure it from infects. Wool is often freed from the greafe by the farmers when they wifh to fell it at a high price; but in the fubfequent manipulations it is greafed or oiled before it is combed, fpun, \&c.; and as this fat matter attracts duft, it dirties and thickens the ftuffs. The firft kind of bleaching to which wool is fubjected, is to free it from thefe impurities. This operation is called fcouring. In manufactories it is generally performed by means of an ammoniacal ley, formed of five meafures of river water and one of ftale urine; the wool is immerfed for about twenty minutes in a bath of this mixture beated to fifty-fix degrees; it is then taken out, fuffered to drain, and then rinfed in running water: this manipuldtion foftens the wool, and gives it the firft degree of whitenefs; it is repeated a fecond, and even a third time, after which the wool is fit to be employed. In fome places fcouring is performed with water fightly impregnated with foap; and, indeed, for valuable articles this procefs is preferable, but it is too expenfive for articles of lefs value.

Fulling the cloth adds ftill to the whitenefs, and if a new degree be neceffary it nuuft be procured by the action of the fulphurous acid; that is to fay, of the fumes of fulphur in a ftate of combuition, or that acid vapour condenfed and combined with water.

Sulphuring is generally performed in an arched or very clofe chamber, conftructed in fuch a manner that the articles to be expoled to the action of the fulphur can be furpended on poles. The chamber being filled, a certain quantity of fulphur is put in a Atate of combuftion on flat difhes having a large furface with very little depth: the entrance is fpeedily thut, and all the interftices around the door are carefully ftopped to prevent the azcefs of the atmofpheric air. The acid generated by the combuftion of the fulphur penetrates the ftuffs, attacks the colouring matter, deftroys it, and effects the bleaching. The ftuffs are left in the fove fome time after the deflagration has ceafed. This time varies from fix to twenty-four hours. They are then taken out, and made to pafs through a light wafhing with foap, to remove the roughnefs they have acquired by the action of the acid, and to give them the neceffary foftnifs.

A fimple defcription of this procefs thows how imperfect it is. At firft the acid of the fulphur acts only on the furfaces, and does not penetrate them. This aërial immerfion 
is not fufficient; the gas cannot introduce itfelf to a fufficient depth into the ftuffs, and the fuperficies only is whitened. By taking advantage of the intimate knowledge which we have of the nature of this acid, we have difcovered a procefs much fimpler, more oconomical, and more agreeable to the principles of fcience.

The fulphurous acid, or that acid generated by the imperfect combuftion of fulphur, differs from the fulphuric acid (oil of vitriol) by its containing lefs of the acidifying principle, and by being, as we may fay, the mean term between fulphur and the fulphuric acid. As we are defirous that our work thould be underftood in manufactories, we thall fpeak only very briefly of the chemical properties of the fulphurous acid, and hall proceed to the method of preparing it.

Sulphurous acid gas unites very eafily with water, and in this combination it may be employed for bleaching wool and filk. The fulphurous acid in this ftate of liquidity may be prepared by making it traverfe water in a $\bar{n}$ apparatus nearly fimilar to that ufed for preparing oxygenated muriatic acid. The moft cenomical method of obtaining it is, to decompofe fulphuric acid (oil of vitriol) by the mixture of any combuftible matter capable of taking from it a part of its oxygen. In exact experiments of the laboratory, where the chemift is defirous of having great purity, it is obtained by means of metallic fubftances, and particularly by mercury; but for the purpole of which we are treating, where great ceconomy is required, we would recommend the molt common fubftances. We thall therefore give the following procefs :

Take chopped fraw, or fawduft, and introduce it into a matrafs; pour over it fulphuric acid, applying at the fame time heat, and there will be difengaged fulphurous acid gas (vapour of fulphur), which may be combined with water in the following apparatus, and by the following method:

Place long necked matraffes on a furnace, and make them communicate with a tubulated flafk into which a little water has been put to abforb the fmall portion of fulphuric acid (oil of vitriol) that may pars without being decompofed through this firft refervoir. Care mut be taken to apply a fmall fafety-tube, one of the extremities of which muft be immerfed fome lines in the water, to guard againft abforption. A tube with a double bending conducts the acid into fiaks or other veffels, where it muft at length combine with the water.

We would propofe ufing, inftead of the tubulated flank, a cylinder of lead, or of fir, or any white wood, hooped with 
varnifhed iron (to prevent rufting) of a pretty confiderable height, terminating at top with a Wolf's bottle, the bottom of which muft be taken out, and which is to be placed in a collar formed in the leaden cylinder; care being taken to cement it with a luting of wax to render it impermeable to fluids. This capital of glafs will enable the operator to fee the quantity of air bubbles difengaged from the furface of the water, and thus to appreciate the progrefs of the faturation, while the weight of this narrow and high column of waler preffing on the bubbles of fulphurous acid gas, in proportion as it is difengaged from the extremity of the tube at the bottom of the cylinder, will facilitate its combination with the water, and accelerate its folution in that fluid. That nothing may be loft, two or three of thefe cylinders can be united in the fame way as is done with a feries of Wolf's bottles. A cock adapted to the bottom of each cylinder will facilitate the difcharge into the immerfing tubs.

The apparatus which we would employ for the immerfion of woollen and filk ftuffs in leys of fulphurous acid are perfeetly fimilar to that which we thall defcribe hereafter for immerfion in oxygenated muriatic acid, and which we have conftructed according to the principles of Rupp*. It was by reafoning upon his apparatus with $\mathrm{C}$. Widmer, of Joux, that we conceived the defign of the prefent one, which is now making at the manufactory of Effone. Let us fuppofe an oblong box, divided in the middle by a partition, and on each fide of it a large reel, on one of which the ftuff is rolled up: in each angle are placed rollers, over which the ftuff is conveyed before it paffes the partition, and traverfes a like number of rollers, which conduct it to the other reel. The object of this difpofition is to caufe the ftuffs to pafs through the bleaching ley, and to expofe to its action the greateft furface poffible.

To turn theie reels, an axis or column of glafs paffing through a collar of leather is employed. One of the extremities of this axis, which is fquare, is inferted into the axis of the reel, while the other is adapted to a bandle, which gives it a rotary motion. By this difpofition there is no need for employing any metallic fubftance internally. To prevent the difperfion of the gas, the covering of this apparatus is furnifhed with a border which fits exactly into the box, and of which an inch, at leaft, ought to be immerfed into the deterfive liquor.

* For an account of Mr. Rupp's procefs and apparatus here alluded to, fee Manchefter Tranfactions, vol. v.; or Philofophical Magazine, vol. ii. -EnIt. 
For bleaching woollen ftuffs we propofe the following method:-The flufs are firft to be scoured by a flightly alkaline ley in the proportion of a pound of potath to 50 pounds of wool; the ley mult be heated to the temperature of 30 degrees : the old procefs, by means of ftale urine, altready mentioned, may be alfo employed. Unine is preferred, becaufe it holds in folution only a fmall quantity of falt incapable of hurting the wool. When the greafe is diffolved, and the wool has been perfectly rinfed, it is to be wafhed in warm foapy water: this part of the fcouring procefs is performed fometimes in the fulling-mill, fometimes with beaters, and fometimes by treading in the tub. In all thefe cafes the ftuffs mult be freed from greafe by repeated wafhings before they are fulphured. If a very bright whitenefs be required, it will be proper to expofe them to heat a fecond, and even a third time, always in water a little foapy, made with two ounces of that fubstance for each pound of wool. It will be better to repeat this operation, turning the ftuff for half an hour at each immerfion with a ftick, than to run the rifk, by too ftrong a ley, of injuring the quality of the wool. After the ftuff has been carefully rinfed it is carried to the tubs to be immerfed in liquid fulphurous acid, or fulphur water, as the workmen term it: the pieces are rolled upon the reels, and are drawn through the fulphurous acid by turning them untii it is obferved that the whitenefs is fufficiently bright. They are then taken out, and left to drain on a bench covered with cloth, left they thould be ftained in confequence of the decompofition of the wood by the fulphurous acid: they are next wahled in river water, and Spanin white is employed if it thould be judged neceffary. This operation is performed by paffing the pieces through a tub of clear water in which about eight pounds of Spanith white have been diluted. To obtain a fine whitenefs, the fluffs, in general, are twice fulphured. According to our procefs, one immerfion and reefing for two or three hours is fufficient. Azuring or blueing is performed by throwing into the Spanifh-white liquor a folu ion of one part of Pruffian blue to four hundred parts of water, thaking the cloth in the liquid and reeling it rapidly:

The operation is terminated by a @ight wathing with foap, to give fofinefs and pliability to the ftuffs. The final operations of drying, ftretching, preffing, \&cc. are foreign to the proceffes which are the object of this effay.

Before venturing thus to retommend the ufe of the liquid fulphurous acid, we made a great many experiments on fpun wool and woollen fuffs, and always with the moft complete fuccefs. 
of Silk.

Silk is a diaphanous matter fpun by a caterpillar, and formed of a fubitance contained in its body, which becomes hard in the air. This infect inhabits warm climates, being indigenous in Afia : it was naturalized in Europe about the time of the downfal of the Roman empire.

The filaments prepared by the filkworm are rolled up in a cod or ball. In the ftate in which we find it, it is covered with a yellow varnifh, which deftroys its brilliancy.and renders it rough. Silk by chemical analyfis gives carbonate of ammonia and oil; water at a boiling heat produces no effect upon it; alcohol makes it experience no change, but concentrated alkaline leys attack and diffolve it.

To give fplendour to filk, it muft be freed from its varnifh. This covering is foluble in alkaline leys. Silk is fcoured by means of foap, which ought always to be chofen of a good quality for fear of ftaining it, and fometimes with diluted muriatic acid. Silk by being fcoured with foap lofes a fourth of its weight. The matter difengaged from it is exceedingly fœetid: if a fkain of filk be not wathed in abundance of water after being fcoured, it will become hot in a few days, putrid fermentation will take place, and fmall white worms will be produced, which will devour the glutinous and faponaceous matter that remains in the filk. The liquor in which it is boiled putrefies, and becomes ufelefs. Macquer has very properly obferved, that if the yellow varnifh can be precipitated to the bottom of the foapy liquor before putrefaction takes place, the foap may be recovered, and the dyer will thus make a confiderable faving.

Even when the beft foap is ufed, it is generally fufpected that it injures the whitenefs of the filk. The fplendour of the Chinefe filks is brighter than that of the European, and the Chinefe employ no foap in their operations. We remember that the Academy of Sciences propofed a prize for a method of fcouring without foap, which was gained by Rigaud, who performed it by a night alkaline folution. Colomb even diffolved the varnith of filk in water, notwithftanding the opinion entertained of its infolubility in that liquid. He expofed the raw filk for nine hours to ebullition, and freed it from the varnith with the lofs of a fourth of its weight.

Notwithftanding the whitenefs which filk acquires by thefe different operations, it mut be carried to a higher degree of fplendour by expofing it to the action of fulphurous G 4 acid 
acid gas in a clofe chamber, or by immerfing it in that acid in a liquid ftate.

\section{Of the Bleacbing of Silk.}

To obtain the complete bleaching of filk it is fubjected to feveral operations. 'The firft tends to deprive it of the gum and colouring matter which externally cover its filaments; the fecond, to give it a jult degree of whitenefs: fometimes the fcouring is feveral times repeated; it is then baked, blued, and fulphured.

It is freed from the gum by a ley of foap and foft water, in the propartion of from twenty-five to thirty pounds of the fineft kind of foap for a hundred pounds of filk. The boiler is then expofed to the action of the fire, and the heat is fo far kept down by a little cold ley, as to maintain, as uniformly as puffible, the temperature of about yo degrees of Fahreitheit. The filk is turned, to expofe all the parts of the fkains to the action of the bath. The fkains are then twifted on the wringer to free them from the ley. They are put into bags of coarle cloth in packets of about twenty-five pounds.

The baking, as the workmen term it, though a boiling, is performed by throwing all thefe bags into'a kettle of frelh ley compoferl as the preceding, making it boil for two or three hours, and ftirring it often with a batton left the filk thould adhere to the bottom: it is then taken from the bags, after which it is opened and fpread out. When the Akains have been fuffered to drain they are again wrung, and then rinfed in a ftream of water. When they have been well wathed and beat in the running water, they are examined, to fee whether there be any fpots not diffolved which may render if neceffary to repeat the operation.

To give it whitenefs, a foapy ley is prepared of four ounces of foap for each pound of filk, diluted with water till il form a good lather when well ftirred and beaten. The fame heat is maintained as in the preceding operations, and never that of boiling water; the filk is preffed for half an bour at leaft, and after being turned for an:ther half hour it is removed; and, not unfreguently, it is baked before it is fubjected to the ope. ration of fulphuring.

This wbite baking is performed in a ley fimilar to that above defcribed, and in bags like thof employed for boiling the Glk in its raw ftate. This baking finithes the bleaching with foap. The filk being taken from the bags is wrung, and rinfed in running water. If an azured white be required, it is made to pals through blue; after being azured, and when 
when the filk is dry, it is then fulphured, and the bleaching is complete.

All thefe proceffes are exceedingly deftructive: thofe which I am about to propofe will make a total change in the method of bleaching filk. I have already mentioned the prize granted by the Academy to Rigaud for fcouring by means of a nightly alkaline ley, and the fuccefs obtained by the abbé Colomb in having fucceeded to diffolve the varnith of filk by the action of boiling water at a very high temperature : thefe inconteftable facts furnith more than the neceffary proofs of the goodnefs of our method.

Take a folution of cauftic foda, fo weak as to mark only a fourth of a degree at moft of the areometer for falts, and fill with it the boiler of the apparatus for bleaching with fteam. Charge the frames with fkains of raw filk, and place them in the apparatus until it is full; then clofe the door, and make the folution boil. Having continued the ebullition for twelve hours, flacken the fire, and open the door of the apparatus. The heat of the itean, which is always above 250 degrees, will have been fufficient to free the filk from the gum and to fcour it. Wafh the fkains in warm water, and, having wrung them, place them again on the frames in the apparatus, to undergo a fecond boiling. Then wath them feveral times in water, and immerfe them in water fomewhat foapy to give them a little foftnefs.

The laft degree of bleaching is effected by making the fkains to pafs through fulphurous acid, making ufe of the procefs and apparatus before recommended for bleaching wool, and which fupplies here the place of fulphuring. The incalculable advantage of this procefs in comparifun of any other, confifts chiefly in the polfibility of following its operations progreffively, and without running the rifk of injuring the quality of the filk by ton violent leys.

\section{Of the Bleacbing of Vegetable Matters.}

The characters and properties of vegetable fubftances are widely different from thole we have delcribed. As organic matters, they contain oxygen, hydrogen, and carbon; but azote, which acts fo important a part in the animal kingdom, is rarely found in them, and much lefs phofphorus and fulphur.

The fubftances found in the interior of plants are, like thofe obferved in the interior of organized bodies, the refult of vegetable fecretion. The nourifhment of vegetables is derived from the bofom of the earth, and this combination of principles 
ciples, abforbed by the roots, with the juices affimilated in their vafcular veffels, produces new compounds.

The deftruction of plants exhibits phænomena which have very little refemblance to thofe exhibited by the diffolution of animal bodies; but the laft refult is always the natural deftruction of the combination of their conftituent principles, the union of hydrogen and oxygen forms water, and the combination of oxygen and carbon forms carbonic acid. It is on thefe principles and modifications, applied to the treatment of vegetable matters, that the art of deftroying colour is founded; it is a decompofition begun and checked in proper time, or the deftruction of fome principles in order to preferve others.

To bleach vegetable fubftances requires the concurrence of feveral menftrua or deterfive fubftances; fuch as foda, oxygenated muriates, calcareous fulphuret, and foap. There are feveral proceffes for depriving hemp, flax, and cotton, of their colour, which may be claffed in the following order:

Ift, Bleaching in the open air, with the affiftance of alkali and foap.

2d, Bleaching by water alone.

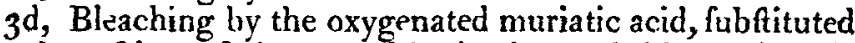
for the action of the atmolpheric air; and this method is divided into four diftinet proceffes : the firft confifts in employing the oxygenated muriatic acid alone; in the fecond, potath is mixed with this acid to condenfe the gafeous vapour and deftroy its fuffocating odour; for the third, oxygenated muriates diffolved in water are employed; and in the fourth, fulphuret of lime is united with this acid.

$4^{\text {th }}$, Bleaching by the fteam of alkalino-cauftic water, where the air and folutions of oxygenated muriates coincide alternately with the action of the fteam.

\section{Of Hemp and Flax.}

If hemp and flax be examined immediately after they are pulfed, we obferve an union of fibres cemented together, which form filaments; thefe fibres are moiftened by the fap, and the ftalks, formed of bundles of filaments, are enveloped in a femi-ligneous fubftance, and covered with a very thin bark. The fap of textile plants differs from thofe of ligneous plants; it approaches near to extractive matter; it is neither faponaceous, nor refinons, nor aquenus, but it poffeffes fomething of all thefe properties: it is foluble in water like the fap of wood, it precipitates itfelf in flakes by the action of oxygenated muriatic acid, but thefe two kinds of fap are diftinguiflied 
by one very ftriking character: that of trees almoft always contains tanning principle, or gallic acid; that of textile plants never poffeffes any. The fap, therefore, is nothing elfe than real vegetable chyle; a nutritive juice, compofed of water, mucilage, and fugar, with fome portions of carbon, phofphorus, and lime.

Thefe preliminary obfervations are indifpenfably neceffary for cumprehending the theory of the operations to which hemp and flax are fubjected. Deprive thefe plants of their fap as foon as they are pulled, decompofe the extracto-mucilaginous matter, which occafions the aggregation of their filaments, and you will have performed the firft operation, which is called watering. The hemp or flax, tied up in bundles, is immerfed in ftagnant or fpring water, in which the bundles are preffed down by means of ftones. Well water and brackith water mut be carefully avoided, os well as that which flows over gypfeous foil. Such water accelerates putrefaction, and hurts the quality of the hemp and flax. This is perfectly agreeable to the principles of chemiftry; it is thus that a liule falt accelerates animal putrefaction, while a great deal tends to prevent it. The portion of faline fubftances taken up by the water haftens corruption by extending the putrid fermentation, which ought to operate only on the juices, even to the filaments, which it blackens and fpoils.

The fibres of flax are feparated by letting them remain in ftagnant water until the mucilaginous membranes which connect them are deftroyed by putrefaction. During its immerfion their fap is decompofed and diffolved, the bark feparates from the ligneous body, and the fibres are infulated. Some days are fufficient for the procefs of watering.

To afcertain the period of watering, which always varies according to the kind of plants, the degree of their maturity, and the nature of the fap, a handful of the flax is taken from the pond, and broken and rubbed between the fingers: if the ftalks are fill green, but brittle, and break with the leaft effort, the bundles muft be taken out : a longer immerfion might extend the decompofition even to the fibrous texture. The putrefcence decompofes the water; there is formed carbonated hydrogen peftilentially foetid; the fifhes die, and the air becomes infected. In countries where a great deal of hemp and flax are cultivated, there are laws which forbid thefe fubftances from being watered in rivers and other ftreams.

The hemp and flax, when taken from the water, are fpread out on the grafs to dry. During the fermentation and de- 
compofition which thence refult, there is a fpeedy combination of oxygen and carbon. Expofure on the grafs facilitates the efcape of the carbonic acid into the atmofphere. The plants become of a whition gray colour, which is called a flaxen gray.

It is known that a ley very dightly alkaline may be fubftituted with advantage for this long and noxious operation: it is therefore certain that a chamber of from 20 to 30 feet in length, into which the fteam of alkalino-cauftic water of the ftrength of one-fourth of a degree only is introduced, will be fufficient to produce the fame effect as watering, on an immenfe quantity of hemp and flax fufpended on bafketwork, in lefs time and with lefs expenfe than are required for the different manipulations of watering. The loffes occafioned by the negligence of workmen, who, by fuffering the hemp and flax to macerate too long, give time to the decompofition to reach the filaments, which renders them brittle and occafions a confiderable wafte, will alfo be avoided. In our procefs the artift can follow every moment the progrefs of his operation, and ftop it at the favourable period.

Hemp and flax, after being watered, muft be dried in a kiln or ftove. A fibrous Releton which exhibits a number of fmall tubes, the interior of which is compofed of a fibrous tiffue, and the exterior of a ligneous, will then be obtained : one of thefe mult be preferved, and the other rejected. This is the object of the fubfequent operations of beating, heckling, \&c.

The ligneous tiffue, or this bark, as the workmen call it, is thrown away as ufelefs, and a certain portion of the fibres of the hemp and flax, which ftill adberes to it, is thus loft, notwithftanding the care of the workmen during thefe different manipulations.

In the neighbourhood of mills, where the operations of beating, heckling, \&c. are performed, I have feen heaps of that fubftance thrown away: it cannot be converted into manure, on account of the long time required for its decompofition; and I have often lamented the lofs of a matter fo valuable, and which might fo eafily be employed for fome ufeful purpofe. By macerating it in water, and fubjecting it to the other operations of a paper manufactory, it may be converted into pulp proper for the fabrication of every kind of paper*: it might even be previounly bleached, or bleached in the ftate of pulp, by the different proceffes which are the

* In Britain this fubftance is often fo made ufe of.-EDit. 
object of this effay. The price of rags is already high enough, befides their fcarcity; and Belgium, the ci-devant Britanny, Auvergne, Alface, \&c. are every year covered with heaps of this fubitance, which the paper-makers might procure at a very low price, and which would afford a rich mine to be worked by the induftrious artift.

Hempen and linen cloth, when they come from the hands of the weaver, are charged with flour pafte called dreffing, employed by the manufacturers to aid the tenfion of the threads during the weaving: fome manufacturers immerfe their cloth in tubs, or expofe them in running water, of boil them, to free them from this fubftance. Thefe are bad methods, which betray abfolute ignorance of the proper principles. The beft is to immerfe the cloth from forty-eight to fifty hours in a tub filled with foft water, at the temperature of from $60^{\circ}$ to $75^{\circ}$ : the kind of fermentation which enfues is fufficient to decompofe the pafte, and is never ftrong enough to attack the filaments of the thread: the cloth is then to be rinfed in running water, by the help of a fluted cylinder, which entirely frees it from that amylaceous fubftance.

This operation gives to cloth a firft degree of bleaching, which arifes merely from the deftruction of a part of the colouring matter during the fermentation, which opens the threads of the cloth, flackens and foftens their tiffue, and fwells their fibres: it may be feen that it has reached its proper term by obferving all thefe phænomena, and when the colour of the cloth is uniform throughout.

After the cloth has been completely rinfed in running water with the cylinder, it remains of a grayin white colour: the tint which oppofes its perfect whitenefs arifes from extractorefinous matter which remains combined with the filaments, and from which they muft be freed. This is the operation properly called bleaching, whatever may be the operation employed for accomplining it. Thefe different proceffes will be defcribed in the courfe of this work.

\section{Of the colouring Matter of Hemp and Flax.}

Before we proceed to a defcription of the different proceffes for bleaching, it is of importance that we thould fay a few words refpecting the colouring matter of flax. This fubject has been fully treated of by the celebrated Kirwan, from whofe experiments it is abundantly proved that the colouring matter extracted by the aetion of alkalies is a peculiar refin, which differs from pure refin by being infoluble in effential ails, and in having fome refemblance to lacks. Having procured fome of this fubitance, by feparating it from what 
the workmen call dead ley, by faturating the alkali with acids, and in that manner obtaining it in the form of a greenith precipitate, which he carefully wathed, he made the following experiments to determine the action of alkalies upon it :

Eight grains of it were digefted in a folution of cryftallized foda faturated at the temperature of $60^{\circ}$ of Fahrenheit : the folution inftantly affumed a dark brown colour. Two meafures of this folution, weighing each 275 grains, were not entirely diffolved by this fubftance; but two meafures of a folution of potalh diffolved the whole of it.

One meafure of cauftic foda, the fpecific gravity of which was I.053, diffolved almoft the whole of it, leaving only a white refiduum.

One meafure of cauftic potafh, the fpecific gravity of which was $1 \cdot 030$, diffolved the whole of it.

One meafure of an alkaline fulphuret, the fpecific gravity of which was $1 \cdot 170$, diffolved the whole matter.

One meafure of ammonia diffolved alfo a portion of this fubftance.

Though thefe experiments were fufficient to fatisfy Kir. wan's doubts, he thought it neceffary to repeat them with the faline fubftances ufually employed in bleaching as well as with foap.

He diffolved, therefore, an ounce of common foda, and as much Dantzic potafh, cach in fix ounces of diftilled water : eight grains of the green matter were put into a meafure of an ounce of each folution, and then digefted for three hours and a half in a heat equal to $180^{\circ}$ of Fahr. The diffolving power of the Dantzic potath was fuperior to that of the foda; for, an ounce of the folution of foda was ftill required, and half an ounce only of the folution of potafh, to diffolve the whole of the fubftance.

An ounce of white foap was diffolved in 18 ounces of diftilled water. The folution was turbid, and it could not be rendered tranfparent but by heating it almoft to the point of ebullition, and then the operation was difficult; for when the liquor, by chance, began to boil, it was thrown to the diftance of more than three feet from the matrafs. Three ounces of this folution were required to diffolve eight grains of the colouring matter.

In order to compare the refpective ftrength of thefe folutions, it muft be obferved, that an ounce of the foda of the thops contains only II4 grains of pure foda: fuppofe the folution to have been made in fix ounces of water, each ounce of water will contain 19 grains of pure alkali, while 
an ounce of the like folution of Dantzic potah will contain $5 \circ$ grains.

The deterfive force of lime was tried without fuccefs; three ounces of water, faturated with lime, produced fcarcely any effect on the colouring matter: thefe three ounces contain at moft three grains of pure lime.

\section{Defcription of Apparatus.}

Fig. I. (Plate II.) the new apparatus propofed by the author for preparing liquid fulphurous acid, and which may Terve alfo for diftilling oxygenated muriatic acid. A, a fection of the furnace, which is a fand bath, and contains three flafks (as may be feen in the horizontal fection fig. 2). Each flatk is furnifhed with a bent tube $a$, for pouring in the fulphuric acid; and from it the liberated gas paffes by the tube $b$ into the receiver $B$, which is made of lead. This receiver has five necks (vide fig. 2.): three of them receive the tubes connected with the three flarks, one receives a fafety-tube $c$, intended to prevent abforption, and the $5^{\text {th }}$ the bent tube $d_{\text {, }}$ which connects it with the feries of tall Wolfs $C, D, \&$ c.

Fig. 3. Shows the way in which it is propofed to alter Mr. Rupp's apparatus. 'The ltuff is made to pafs over rollers in the corners, \&c. of the box in going from one reel to another, and the axes come through leather collars in the fide inftead of the top of the box. The engraving reprefents a vertical fection.

Fig. 4, a boiler and fteaming chamber. A, the boiler, charged with ftale urine, rendered cauftic by the addition of quicklime*. The ammonia thus difengaged paffes through the tube $B$ into the chamber $C$, which is furnithed with reels and rollers for winding the ftuff, and thus expofing it to the action of the vapour. At the corner $a$, the uncondenfed vapour can pafs into the worm-tub $D$ to be condenfed, and returned to the boiler by the tube $b c$. Or it may be received. into the tub $\mathrm{E}$ by thutting the cock at $c$, and opening the cock $n$. The opening into the chamber, i.e. the door, is on the top, and fhuts air-tight. With this apparatus, vapour or fteam of any kind may be employed for the purpofe of bleaching.

[To be continued.]

* For this methd of applying ammonia to the purpofes of bleaching. the world is indebted to Mr. Crooks, of Edinburgh, who, a confiderable time ago, took out a patent for it for tingland. The fame gentleman having, alung with $\mathrm{Mr}$. Turnbull. improred the procefs, and extended the principle to the ufe of fixed alkalies allo, allifted by the action of the fteam of boiling water, patents have fince bet $n$ taken out in therr juint names for England, Scotland, and Ireland. Of this invention we gave an account in our ninth volume.-EDIT. 


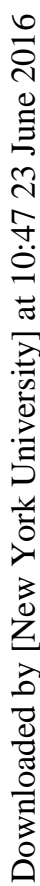
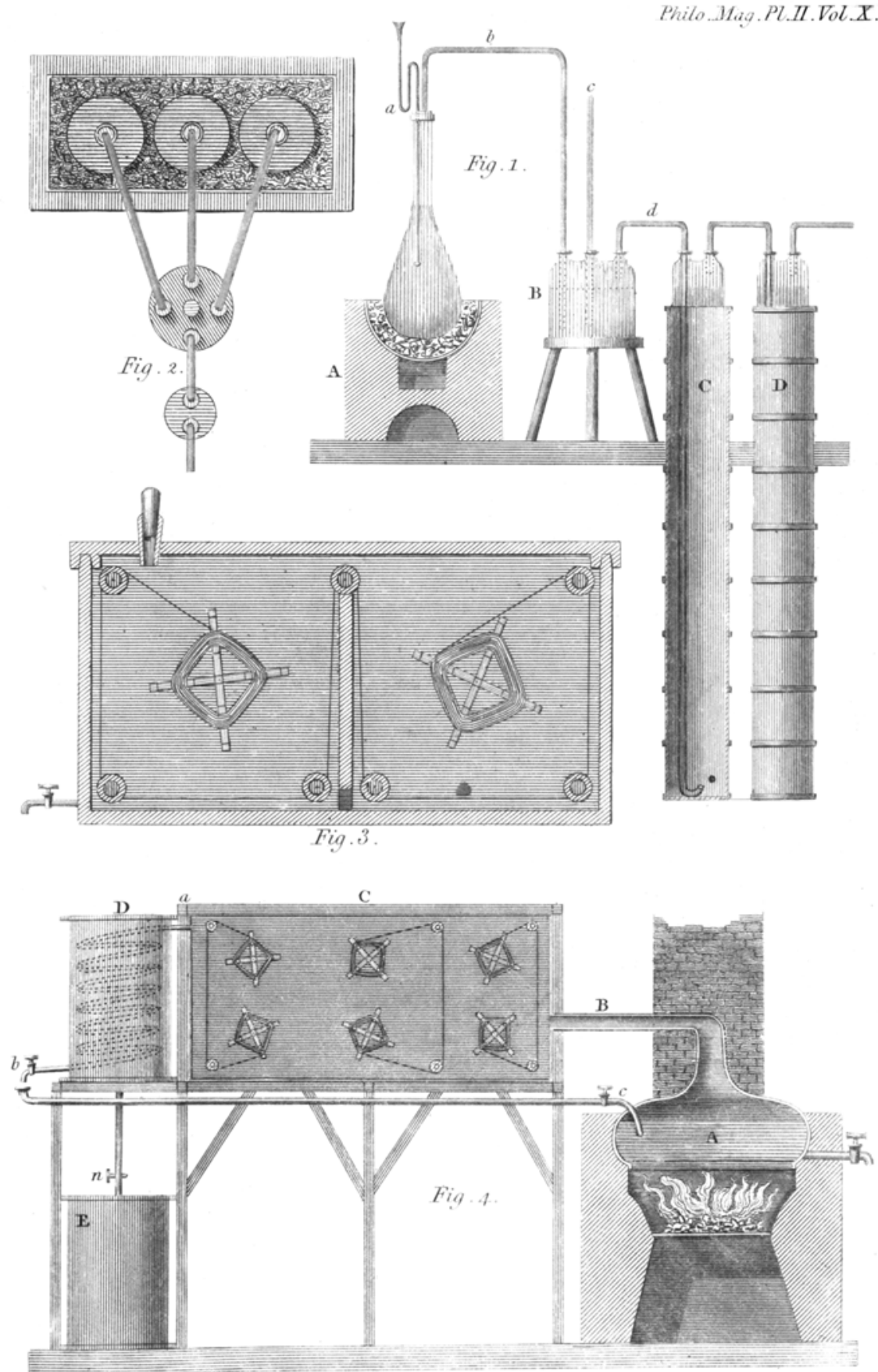